\title{
Fotogrametrik nokta bulutu verisinin makine öğrenmesi ile sınıflandırılması
}

\author{
Muhammed Enes Atik ${ }^{1^{*}}$ D , Ömercan Güngör ${ }^{1}$ D , Engin Keskin ${ }^{1}$ D, Zaide Duran ${ }^{1}$ (D) \\ ${ }^{1}$ Istanbul Teknik Üniversitesi, Ayazağa Kampüsü, Inşaat Fakültesi, Geomatik Mühendisliği Bölümü, Sarıyer, İstanbul, Türkiye.
}

Öz: Günümüzde bilim ve teknolojinin gelişmesi sayesinde üç boyutlu yeryüzü gerçekliği modellenebilmiş ve harita üretiminde yeni bir sayfa açılmıştır. Özellikle fotogrametrik yöntemlerin gelişmesi ile nokta bulutları birçok alanda kullanılmaya başlanmıştır. Veri boyutlarının büyümesi ve kullanım alanlarının yaygınlaşması ile nokta bulutlarından bilgi çıkarımı önemli hale gelmiştir. Nokta bulutu verileri çok sayıda noktadan oluştuğundan dolayı bu verilerin sınıflandırılması için öğrenme temelli yaklaşımlar kullanılmaya başlanmıştır. Sinıflandırma işlemi için ögrenme temelli yaklaşımlar kullanıldığında, nokta bulutunda yer alan objelerin birbirinden ayırt edilebilirliği artmakta ve model üzerinden yapılacak çalışmalar için kolaylık ve güvenilirlik sağlamaktadır. Karmaşık yapıdaki verinin çözümlenmesi için güçlü matematiksel algoritmalara sahip olan makine ögrenimi kullanımı ilk sıralarda gelmektedir. Bu çalışma kapsamında İstanbul Teknik Üniversitesi Ayază̆a Kampüsü içerisinde belirlenen bölgeye ait insansı hava aracı fotoğrafları kullanılarak nokta bulutu verisi üretilmiş ve dört sınıfa (bina, ağaç, araç ve yer seviyesi objeleri) göre sınıflandırılmıştır. Bu sınıflandırma ișlemi, makine öğrenmesi algoritmalarından Rastgele Orman (RO) ve Çoklu Katman Algllayıcı (ÇKA) algoritmaları kullanılarak yapılmıştır. Kullanılan bu iki farklı algoritmadan RO algoritması ile genel doğruluk \%78.54, ÇKA algoritması ile genel doğruluk \%89.88 oranında elde edilmiştir.

Anahtar Sözcükler: Fotogrametri, Nokta bulutu, Makine öğrenmesi, İnsansız hava arac1, Doğruluk analizi

\section{Classification of photogrammetric point cloud data with machine learning}

Abstract: Today, thanks to the development of science and technology, the three-dimensional earth reality has been modeled and a new page has been opened in map production. Especially with the development of photogrammetric methods, point clouds have started to be used in many areas. Extraction of information from point clouds has become important with the growth of data sizes and the spread of usage areas. Since point cloud data consists of a large number of points, learning-based approaches have been used to classify these data. When learning-based approaches are used for the classification process, the distinguishability of the objects in the point cloud from each other increases and provides convenience and reliability for studies. The usage of machine learning, which has powerful mathematical algorithms, comes first in order to analyze complex data. Within the scope of this study, point cloud data was produced by using aerial photographs taken from unmanned aerial vehicle of the region determined in Istanbul Technical University Ayazağa Campus and classified according to four classes (building, tree, vehicle and ground level objects). This classification process has been done by using Random Forest (RF) and Multi-Layer Perceptron (MLP) algorithms from machine learning algorithms. The overall accuracy was $78.54 \%$ with the $R F$ algorithm, and $89.88 \%$ with the MLP algorithm.

Keywords: Photogrammetry, Point cloud, Machine learning, Unmanned aerial vehicle, Accuracy assessment 


\section{Giriş}

Üç boyutlu (3B) nokta bulutlarının artan kullanım alanları; 3B veriden bilgi çıkarımı, fotogrametri, uzaktan algılama, bilgisayarla görme ve robotikte önemli bir çalışma alanı haline gelmiştir. Lazer tarayıcılar, Lidar, hava fotoğrafları gibi yöntemlerle üretilen nokta bulutları bu çalışmalarda artık sıklıkla kullanılmaktadır. Nokta bulutları, iki boyutlu (2B) görüntülere kıyasla 3B yapısı nedeniyle arazi kullanımı arazi örtüsü uygulamaları (Donmez \& Ipbuker, 2018) için de zengin geometrik bilgiler sağlar. Nokta bulutları büyük veri setleri olduğundan dolayı bunları işleyip, analiz etmek ve üzerinde çalışmalar yürütmek hem zorlu bir süreçtir hem de uzun zaman almaktadır. Geleneksel olarak, nokta bulutu sınıflandırması, her sınıf için noktaları ayırt etmek üzere bir dizi ayrımcı kural tanımlamaya dayanır (Lin, Chen, Su, \& Chen, 2014). Her ne kadar ayrımcı kurallar kontrollü ortamlar için etkili olsa da yöntemler sınıflar arasında çok fazla belirsizlik ve karmaşık ilişkiler içeren karmaşık verilerle uğraşırken hala doğal sınırlamalara sahiptir. Bu nedenle, bu karmaşık veriler için nokta bulutu sınıflandırması, basit karar kuralları birleştirilerek ele alınamaz. Makine öğrenmesi, 2B optik görüntülerdeki ve 3B nokta bulutlarındaki karmaşık içeriği sınıflandırmak için kullanılabilecek güçlü bir matematiksel araçtır. Son zamanlarda, bazı araştırmacılar, ayrım bulutunu kullanarak sınıflandırma eksikliklerinin üstesinden gelmek için nokta bulutunu sınıflandırmak için Destek Vektör Makinesi (DVM) ve Rastgele Ormanlar (RO) gibi yerel olarak bağımsız sınıflandırıcıları kullanmışlardır. Makine öğrenme algoritmalarında, sınıflandırma kuralları, önceden belirlenmiş keyfi kurallar ve güçlü varsayımlara dayanan parametreler olarak tanımlanmak yerine, eğitim verileri kullanılarak otomatik olarak öğrenilir. Makine öğrenimi ve otomatik özellik seçimi sayesinde, geleneksel bir sinfflandırma metodolojisinde bulunan zahmetli tasarım ve programlama çalışmalarının çoğundan kaçınılır. Bu nedenle, birden fazla nesne türünden oluşan karmaşık veriler için, makine öğrenme yöntemleri, etkinliklerinden dolayı geleneksel sınıflandırma yöntemlerinden daha elverişlidir (Guo, Huang, Zhang, \& Sohn, 2015).

$\mathrm{Bu}$ çalışmada insansız hava aracı (IHA) fotoğraflarından üretilen fotogrametrik nokta bulutunun makine öğrenmesi yöntemleri ile sınıflandırılması amaçlanmıştır. Bu bağlamda yapılan işlem adımları, çalışma bölgesinde bulunan nesnelerin 4 sınıf (bina, ağaç, araç ve yer seviyesi nesneleri (YSN)) altında toplanması, bu sınıflara ait test ve eğitim verilerinin belirlenmesi, eğitim verileri kullanılarak eğitilen makine öğrenmesi modelleriyle test verilerinin sınıflandırılması olacaktır. Çalışma bölgesi olarak İstanbul Teknik Üniversitesi Maslak Kampüsü İnşaat Fakültesi ve çevresi belirlenmiştir. Sınıflandırma amacıyla Rastgele Orman (RO) ve Çoklu Katman Algılayıcı (ÇKA) algoritmaları kullanılmıştır. Çalışmada noktaları tanımlamak için geometrik özellikler kullanılmıştır. Belirlenen geometrik özellikler; özdeğerlerin toplamı, omnivaryans, özentropi, anistropi, düzlemsellik, yüzey değişimi, küresellik, dikeylik olarak seçilmiştir. Her sınıf için kesinlik, hassasiyet F1 skor ve doğruluk değerleri de hesaplanmıştır. Uygulamayı gerçekleştirmek için Python programlama dili ve açık kaynak kodlu Cloud Compare yazılımı kullanılmıştır.

\section{2. İlgili Çalışmalar}

Nokta bulutundaki her noktaya ayrı ayrı etiketler atamak için genellikle denetimli öğrenme yaklaşımları seçilebilir. Literatürde nokta bulutlarının sınıflandırılması için özelliklerin kullanılmasına dair çalışmalar mevcuttur. Weinmann, Jutzi, Hinz ve Mallet (2015) tarafından yapılan kapsamlı çalışmada nokta bulutu sınıflandırması için farklı özelliklerin kullanımı, en uygun komşuluk seçimi ve farklı sınıflandırıcılar incelenmiş̧ir. Çalışmada üretilen özellikler sadece nokta bulutuna bağlı özelliklerdir. Veri seti olarak mobil lazer tarama verisi olan Oakland 3D Point Cloud Dataset ve yine aynı tür bir veri olan Paris-rue-Lille Database kullanılmıştır. Değerlendirme sonucunda RO en etkili sınıflandırıcı olmuştur. Oakland veri setinde genel doğruluk \%92.25 elde edilmiştir. Vosselman, Coenen ve Rottensteiner (2017) tarafından yapılan çalışmada 19 tane özellik kullanılmıştır. Özelliklerin hepsi nokta bulutunda elde edilmiş 3B özelliklerdir. Önerilen yöntemde nokta bulutu belirli 
gruplara ayırılıp sınıflandırma yapılmıştır. Veri seti olarak Uluslararası Fotogrametri ve Uzaktan Algılama Birliği'nin (International Society of Photogrammetry and Remote Sensing, ISPRS) Vaihingen ve Rotterdam veri setleri kullanılmıştır. Sınıflandırma yöntemi olarak da Koşullu Rastgele Alan algoritması kullanılımıştır. Yapılan çalışma sonucunda nokta tabanlı sınıflandırmaya göre, grup tabanlı sınıflandırma daha iyi sonuçlar vermiştir. Rotterdam veri setinde $\% 91$, Vaihingen veri setinde \%89 doğruluk elde edilmiştir. Belgiu, Tomljenovic, Lampoltshammer, Blaschke ve Höfle (2014) tarafindan gerçekleştirilen çalışmada ise nokta bulutundan bina tespiti yapılımışıı. Bu amaçla kullanılan sınıflandırıcı RO algoritmasıdır. Binalar; küçük binalar, apartmanlar ve endüstriyel binalar olmak üzere 3 sınıfta incelenmiştir. Nokta bulutunda üretilen özellikler kullanılarak sınıflandırıcı eğitilmiştir. Elde edilen özellikler daha çok yükseklikle ilgili özelliklerdir. Kullanılan nokta bulutunun yoğunluğu metrekare başına 4.8 noktadır. 45 örnek kullanılarak eğitim gerçekleştirilmiştir. Sonuç olarak küçük binalar için \%98'lik doğruluk elde edilmiştir. Apartman tarzı yüksek yapılar için \%74, endüstriyel yapılar için \%51'lik doğruluk oranına ulaşılmıştır. Guo vd. (2015) tarafından yapılan çalışmada ise nokta bulutu JointBoost isimli topluluk öğrenmesi yapan bir algoritma ile sınıflandırılmıştır. Topluluk öğrenmesi birden fazla zayıf sınıflandırıcıyı birleştirerek güçlü bir sınıflandırıcı oluşturulmasını amaçlar. Söz konusu çalışmada 5 sınıf hedeflenmiştir: bina, arazi, bitki, enerji hattı ve enerji hattı direkleri. Her bir nokta için nokta bulutundan 26 özellik belirlenmiştir. İlk sınıflandırma için en etkili 17 özellik belirlenmiştir. Kullanılan nokta bulutu metrekare başına 60 noktalık yüksek bir yoğunluğa sahiptir. Yapılan sınıflandırma iki aşamaya sahiptir. İlk aşamada JointBoost yöntemi ile sınıflandırma yapılmaktadır. Sonraki aşamada ise güvenilir olmayan veya yanlış sınıflandırılmış noktalar tekrar sınıflandırılır. Bu aşamada $\mathrm{k}$-en yakın komşu yöntemi kullanılır. Böylece sınıflandırma sonucunda iyileşme sağlanmıştır. Sınıflandırma sonucu 500 bin ve 5 milyon noktaya sahip iki farklı bölgede elde edilmiştir. İlk bölgedeki doğruluk \%97.48, ikinci bölgedeki doğruluk \%95.03 olarak gerçekleşmiştir. Li, Cheng, W. Chen ve G. Chen (2015)'te yapılan çalışmada nokta bulutunda heyelan bölgeleri tespit edilmiştir. Bu amaçla nokta bulutunda üretilen Sayısal Arazi Modeli (SAM) ve hava fotoğrafları kullanılmışıı. İlk olarak SAM üzerinden eğim gradyanı, plan eğriliği, pürüzlülük, açıklık ve gökyüzü görünümü faktörü gibi piksel tabanlı toplam 52 özellik belirlenmiştir. Sonrasında bu özellikler Nesne Tabanlı Görüntü Analizi ile belirlenen nesnelere aktarılmıştır. Özellik sayısı çok fazla olduğu için sınıflandırmadan önce özellik seçimi yapılmıştır. Bu amaçla RO tabanlı bir nesne seçim algoritması kullanılmıştır. Çalışmada sınıflandırıcı olarak Rastgele Orman ve DVM algoritmaları kullanılmışıı. Doğruluklar RO için \%77.36 ve DVM için \%76.87 olarak elde edilmiştir. Plaza-Leiva, Gomez-Ruiz, Mandow ve Garcia-Cerezo (2017) tarafindan yapılan çalışmada ise kovaryans analizinden elde edilen mekânsal şekil özelliklerinin denetimli öğrenme sınıflandırmasının hem hesaplama yükü hem de doğruluğunda etkinliğinin geliştirilmesine odaklanmaktadır. Bu amaçla nokta bulutundan her bir nokta için özdeğerler hesaplanmıştır. Sınıflandırmada şehir yapıları, doğal bitki örtüsü ve yapay bitki örtüsü olmak üzere üç sınıf üzerine yoğunlaşılmıştır. 4 farklı denetimli öğrenme algoritması karşılaştırılmıştır: DVM, yapay sinir ağı, Gauss işlemi, Gauss karışım modelleri. Yapılan çalışma neticesinde DVM için \%53, yapay sinir ağı için \%84, Gauss işlemi için \%82 ve Gauss karışım modelleri için \%95 doğruluk elde edilmiştir. Cabo, Ordóñez, Sáchez-Lasheras, Roca-Pardiñas ve de Cos-Juez (2019) tarafından yapılan çalışmada yerleşim bölgelerinde ve ormanlık bölgelerde denetimli sınıflandırma ile sınıflandırma yapılmıştır. Çalışmada nokta bulutundan doğrusallık, düzlemsellik, küresellik, yataylık ve yükseklik değişimi olmak üzere 5 adet geometrik özellik kullanılmışır. Sınıflandırma algoritmaları olarak DVM, RO, lojistik regresyon ve lineer diskriminant analiz seçilmiştir. Farkı komşuluk çapları kullanılarak yapılan sınıflandırmalar neticesinde yerleşim alanı için yaklaşık \% 80 , ormanlık alan için yaklaşık \%93'lük bir doğruluk elde edilmiştir. En başarılı algoritma olarak RO algoritması ön plana çıkmıştır. Yapılan çalışma incelendiğinde sadece nokta bulutunda elde edilen geometrik özellikler kullanılmıştır. Becker, Rosinskaya, Häni, d’Angelo ve Strecha (2018) tarafından yayımlanan diğer bir çalışmada ise geometrik özellikler kullanılarak nokta bulutlarının denetimli sınıflandırması yapılmıştır. Çalışmada 15 tane geometrik özellik yanında noktaların renk bilgisini de içeren 4 farklı veri seti kullanılmıştır. Sınıflandırıcı algoritma olarak RO ve Gradyan Artıran Ağaçlar seçilmiştir. Sınıflandırma sonucunda hedeflenen sınıflar yer, yüksek bitkiler, yol, araba, bina ve insan yapımı nesnelerdir. 
Eğitim ve test amacıyla fotogrametrik nokta bulutu kullanılmıştır. Çalışma neticesinde elde edilen doğruluk sadece geometrik özellikler için ortalama \%50, renk bilgisi eklendiğinde ise \%70’lere ulaşmaktadır. Atik, Duran ve Seker (2021) tarafından geometrik özellikleri kullanan sekiz kontrollü makine öğrenimi yönteminin performansı üzerine kapsamlı bir çalışma yayınlanmıştır. Çalışmada farklı ölçeklerde elde edilen destek alanının sınıflandırma doğruluğuna etkisiyle birlikte geometrik özelliklerin önemi verilere ve ölçeğe göre incelenmiştir. Çalışmada Lidar ile elde edilen Dublin City, Oakland3D ve Vaihingen veri setleri kullanılmıştır. Atik ve Duran (2021) tarafından yapılan diğer bir çalışmada, popüler tekrarlayan sinir ağı algoritmaları LSTM ve BiLSTM ile fotogrametrik nokta bulutu sınıflandırması yapılmıştır. Çalışma, önerilen yeni bir fotogrametrik veri seti üzerinde gerçekleştirilmiştir. Sınıflandırmada sadece geometrik özellikler değil, renk bilgisi de kullanılmıştır. Böylece renk bilgisinin sınıflandırmaya etkisi de incelenmiştir.

$\mathrm{Bu}$ çalışmada yeni bir fotogrametrik veri seti oluşturularak makine öğrenmesi algoritmaları ile nokta bulutu sınıflandırması yapılmıştır. Literatürdeki çalışmalarda çoğunlukla Lidar ile elde edilen nokta bulutları kullanılmıştır. Fotogrametrik veriler yoğun ve Lidar nokta bulutlarına göre daha gürültülü oldukları için etiketli veri oluşturmak emek-yoğun bir süreç gerektirmektedir. Diğer bir önemli nokta fotogrametrik nokta bulutları görüntülere uygulanan ileri işleme adımları ile elde edildiği için Lidar kadar kolay elde edilememektedir. Genellikle çalışmaların Lidar üzerine yoğunlaşmasının temel sebepleri bu şekilde açıklanabilir. Ancak fotogrametrik nokta bulutlarının artan kullanımı ile sınıflandırma açısından değerlendirilmeleri gerektiği açıktır. Fotogrametrik nokta bulutlarının Lidar nokta bulutlarına göre daha yoğun yapıya sahip olması, arazi üzerindeki nesneleri ve yüzeyleri daha iyi tanımlanmasını sağlamaktadır. Fotogrametrik veriler ile yapılan çalışmaların kısıtlılığı göz önüne alındığında çalışma önemli bir özgün değere sahiptir. Ayrıca Türkçe literatüre de önemli bir katkı sunulmaktadır. Literatürdeki fotogrametrik nokta bulutları ile yapılan çalışmalarında veriler paylaşılmadığı ve gerçek bir verinin kullanılması amaçlandığı için bu çalışmada kullanılmak üzere bir nokta bulutu üretilmiştir. Lidar nokta bulutlarından farklı olarak fotogrametrik nokta bulutları renk bilgisi içerdikleri için geometrik özelliklerin yanında renk bilgisi de özellik uzayına dahil edilmiştir. Geometrik özellikler ile beraber renk bilgisinin kullanımı sınıflandırma doğruluğuna olumlu etki yapmaktadır (Atik \& Duran, 2021).

\section{Veriler ve Yöntem}

\section{1 Çalışma Alanı ve Kullanılan Veri}

İstanbul Teknik Üniversitesi (İTÜ) Ayazağa Yerleşkesi çalışma alanı olarak seçilmiştir (Şekil 1). Alan, iyi dağıtılmış farklı arazi kullanımı ve arazi örtüsü sınıflarını içermektedir. Çalışma alanı seçilirken, seçilecek olan bölgede yer alan doğal ve yapay objelerin projede kullanılacak olan obje sınıflarını içermesine dikkat edilmiştir. 


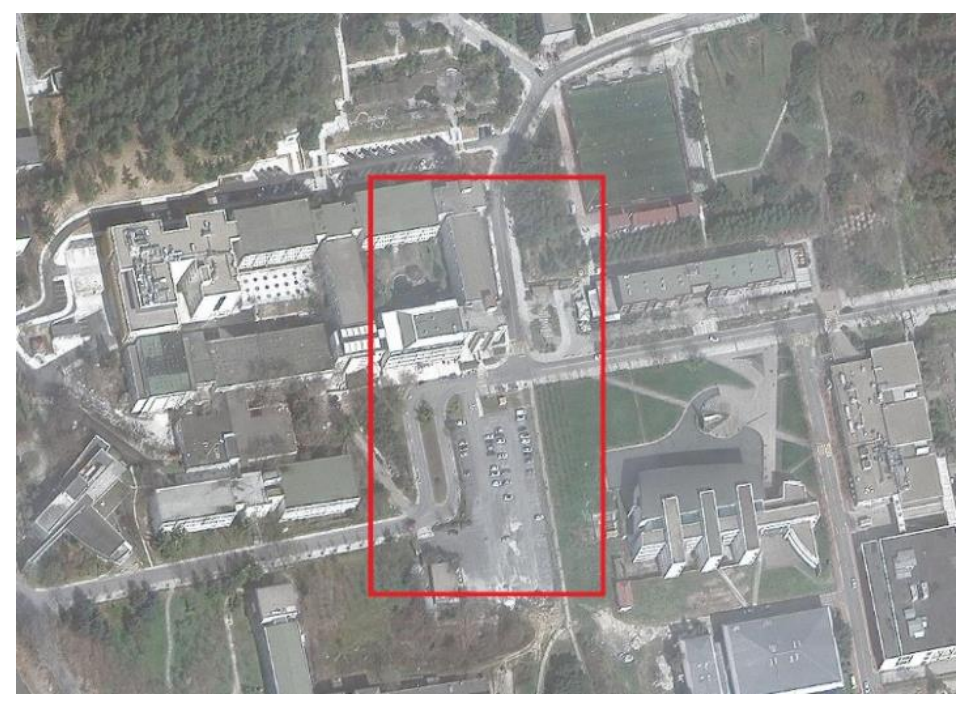

Şekil 1: Çalışma bölgesi uydu görüntüsü.

Bu çalışmada, İTÜ Kampüsünde yüksek çözünürlüklü görüntüleri yakalamak için DJI Mavic 2 Pro platformu üzerinde bir DJI optik kamera kullanılmıştır. Kamera görünür bantlarda algılama yapmakta ve 84 derece yatay görüş alanı (Field of View, FOV) ile $5472 \times 3648$ görüntü boyutunu yakalayabilmektedir. Kameranın etkin piksel boyutu $20 \mu$ m ve lenslerin odak uzaklığı 8.8 mm'dir. Görüntüler $3 \mathrm{~cm}$ zemin örnekleme mesafesine (Ground Sample Distance, GSD) sahiptir. Uçuş parametreleri olarak \%80 boyuna örtü oranı ve \%70 enine örtü oranı kullanılmıştır (Şekil 2). Uçuş yüksekliği 80 m olarak seçilmiştir. Nokta bulutu üretimi Agisoft Photoscan yazılımı kullanılarak fotogrametrik işlem adımları uygulanmıştır. Nokta bulutları ayrıca her nokta için renk bilgisi içermektedir. Noktalar manuel olarak etiketlenmişlerdir. Veri setinin nokta dağılımı Tablo 1'de gösterilmiştir.
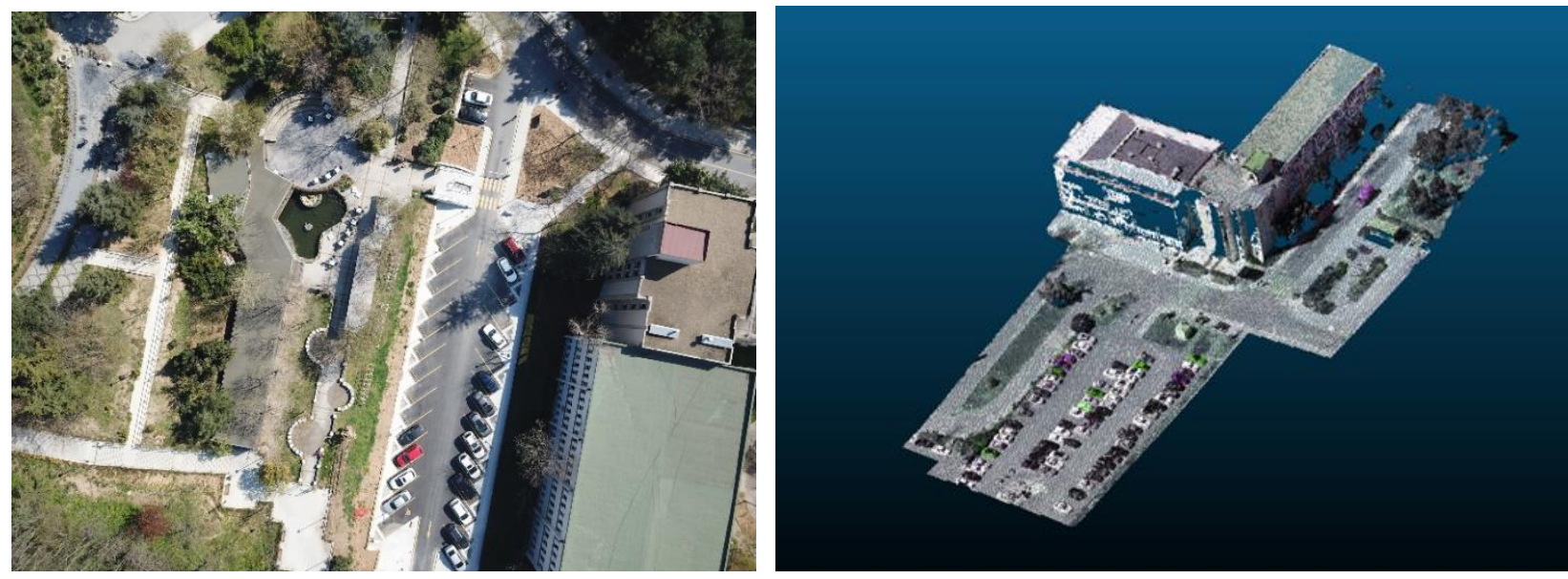

Şekil 2: Hava fotoğrafı örneği (solda) ve üretilen nokta bulutu (sağda).

Tablo 1: Sınıflara ait eğitim ve test noktası sayıları

\begin{tabular}{ccc}
\hline Sınıf & Eğitim & Test \\
\hline Bina & 250000 & 5430865 \\
\hline A ğaç & 250000 & 978754 \\
\hline YSN & 250000 & 13797690 \\
\hline Araç & 250000 & 1872918 \\
\hline
\end{tabular}




\subsection{Rastgele Orman}

RO (Breiman, 2001), korelasyonu olmayan ağaçların geniş bir koleksiyonunu oluşturan ve daha sonra bunların ortalamalarını alan torbalamanın geliştirilmiş versiyonudur. Birçok problemde RO’ların performansının yükseltilmesindeki (boosting) yöntemler çok benzer olup, eğitilmesi ve ayarlanması daha kolaydır (Hastie, Tibshirani, \& Friedman, 2010).

RO'daki her ağaç bir sınıf tahmini verir ve en çok oy verilen sınıf modelin tahmini haline gelir. RO, torbalama olarak bilinen değiştirme ile veri kümesinden her ağacın rastgele örneklenmesine izin vererek bundan yararlanır (Qin, Guo, Liu, \& Zhao, 2019). Torbalama algoritmasında, bir sınıflandırıcıyı eğitmek için orijinal eğitim veri setinden birden çok önyüklemeli eğitim veri setleri oluşturulur ve her bir ağaca bir eğitim veri seti atanır. Oluşturulan ağaçlar birbirinden bağımsızdır ve tahmin için en büyük oy baz alınır (Akar \& Güngör, 2012). Torbalamayı kullanmanın iki nedeni vardır. Birincisi, torbalama kullanımının rastgele özellikler kullanıldığında doğruluğu arttırdığ1 görülmektedir. İkincisi, torbalamanın, kombine ağaç topluluğunun genelleştirilmiş hata $\left(\mathrm{PE}^{*}\right)$ ile ilgili tahminlerin yanı sıra güç ve korelasyon tahminlerini de vermek için kullanılabilmesidir (Breiman, 2001).

RO sınıflandırıcısı ile bir ağaç üretmek için kullanıcı tarafından tanımlanan 2 parametre gereklidir. Bu parametreler, en iyi bölünmeyi belirlemek için her bir düğümde kullanılan değişkenlerin sayısı ve geliştirilecek ağaçların sayısıdır. İlk olarak eğitim veri setinin 2/3'ünden önyükleme örnekleri oluşturulur. Out-of-bag (OOB) verisi olarak da adlandırılan, eğitim veri setinin 1/3'lük geri kalan kısmı hataları test etmek için kullanılır. Elde edilen değerlere göre budama olmadan ağaç geliştirilir (Akar \& Güngör, 2012). Bu işlem sonucunda elde edilen hata genelleştirilmiş hata olarak adlandırılır. Genelleştirilmiş hata hesabı Eşitlik 1'de gösterilmiştir:

$P E^{*}=P_{X, Y}(m g(X, Y)<0)$

mg() marj fonksiyonunu ifade eder. Marj, doğru sınıf için (X, Y)'deki ortalama oy sayısının, diğer herhangi bir sınıf için ortalama oyu ne kadar aştığını ölçer. Marj ne kadar büyük olursa, sınıflandırmaya o kadar güvenilebilir (Breiman, 2001).

\section{3 Çok Katmanlı Algılayıcı}

Tek bir ağırlık tabakasına sahip olan bir algılayıcı, girdinin yalnızca doğrusal işlevlerinin üzerinde çalışabilir. Doğrusal olmayan fonksiyonlar üzerinde başarılı sonuçlar veremez. ÇKA'lar, sınıflandırma için kullanılırsa, bu tür doğrusal olmayan problemleri çözebilir. (Alpaydın, 2010). ÇKA, bir veri kümesi üzerinde eğitilerek bir işlevi öğrenen denetimli bir öğrenme algoritmasıdır. Bir dizi özellik ve bir hedef göz önüne alındığında, sınıflandırma veya regresyon için doğrusal olmayan bir fonksiyon yaklaşımı öğrenebilir. Giriş ve çıkış katmanı arasında, gizli katmanlar olarak adlandırılan bir veya daha fazla doğrusal olmayan katman olabilir (Şekil 3). Bundan dolayı lojistik regresyondan farklıdır (Abdullah, Othman, Kasim, Saharuddin, \& Mohamed, 2020).

ÇKA'da katmanlar arasında ileri ve geri yayılım olarak adlandırılan geçişler bulunmaktadır (Şekil 3). İleri yayılım safhasında, ağın çıktısı ve hata değeri hesaplanır. Geri yayılım safhasında ise hesaplanan hata değerinin minimize edilmesi için katmanlar arası bağlantı ağırlık değerleri güncellenir (Arı \& Berberler, 2017). 


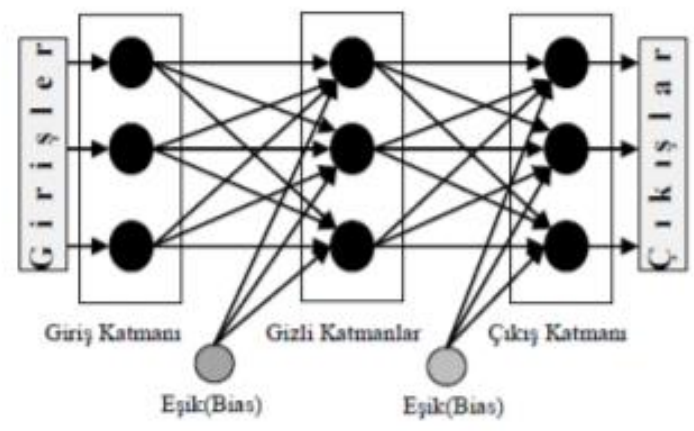

Şekil 3: ÇKA'nın yapısı (Arı ve Berberler, 2017).

Girdi x değeri ile giriş katmanı beslenir. "Aktivasyon" ileri yönde yayılır ve gizli katmanlarda $z_{h}$ değerleri hesaplanır. Her gizli katman birimi kendi başına bir algılayıcıdır ve doğrusal olmayan sigmoid fonksiyonunu ağırlıklı toplamına uygular (Eşitlik 2).

$z_{h}=\operatorname{sigmoid}\left(w_{h}^{T} x\right)=\frac{1}{1+\exp \left[-\left(\sum_{j-1}^{d} w_{h j} x_{j}+w_{h 0}\right)\right]}, \quad h=1,2, \ldots, H$

Eşitlik 2'de $x$ girdi değerini, $w_{h}$ ağırlık vektörünü, $w_{h j}$ ilk katmanın ağırlığını, $j$ girdi indisini, $H$ gizli uzayın boyutunu ve $d$ girdi sayısını ifade eder. Çıkış katmanındaki $y_{i}$ değerlerini hesaplamak için, bu bölümdeki algılayıcılar girdi değer olarak gizli katmanlarda hesaplanan değerleri kullanırlar (Alpaydın, 2010).

\subsection{Geometrik Özellikler ve Renk Bilgisi}

Projede nokta bulutunun iki boyutlu ve geometrik özelliklerden oluşan bir özellik uzayı kullanılarak farklı makine öğrenme algoritmaları ile sınıflandırılması amaçlanmaktadır. Geometrik özellikler nokta bulutunda elde edilmektedir. Bir noktanın kovaryans matrisinden üretilen özellikler, bir nokta bulutunun yerel geometrik özelliklerini tanımlayabilen yaygın olarak kullanılan geometrik özelliklerdir (Weinmann vd., 2015). $\left(\lambda_{1}, \lambda_{2}, \lambda_{3}\right)$ sırasıyla birinci, ikinci ve üçüncü özdeğerdir (Eşitlik $3-10)$.

Özdeğerlerin toplamı $=\lambda_{1}+\lambda_{2}+\lambda_{3}$

Omnivaryans $=\sqrt[3]{\lambda_{1} \lambda_{2} \lambda_{3}}$

Özentropi $=\sum_{i=1}^{3} \lambda_{i} \ln \lambda_{i}$

Anistropi $=\frac{\lambda_{1}-\lambda_{3}}{\lambda_{1}}$

Düzlemsellik $=\frac{\lambda_{2}-\lambda_{3}}{\lambda_{1}}$

Yüzey değişimi $=\frac{\lambda_{3}}{\lambda_{1}+\lambda_{2}+\lambda_{3}}$

Küresellik $=\frac{\lambda_{3}}{\lambda_{1}}$

Dikeylik $=1-\left|\left\langle\left[\begin{array}{lll}0 & 0 & 1\end{array}\right], \lambda_{3}\right\rangle\right|$ 
Fotogrametrik nokta bulutları her bir noktaya ait renk bilgisini de içermektedir. Yansıtım değerleri elektromanyetik spektrumun görünür bölgesinden elde edilmiştir. Red-Green-Blue (RGB) değerleri 0-255 arasında değer almıştır. Böylece her bir noktaya ait 8 geometrik özellik ve 3 renk bilgisi olmak üzere 11 özelliği içeren bir özellik uzayı oluşturulmuştur.

\subsection{Doğruluk Analizi}

Etiketlenen nokta bulutu referans olarak kabul edilerek, sınıflandırılmış nokta bulutları değerlendirilmiştir. Oluşturulan hata matrisleri üzerinden değerlendirme metrikleri olarak kesinlik, hassasiyet, F1 skoru ve genel doğruluk değerleri hesaplanmıştır. Kesinlik, pozitif olarak sınıflandırılan noktaların oranını ölçer (Eşitlik 11). Hassasiyet, gerçek pozitif (GP) olan pozitiflerin oranını ölçer (Eşitlik 12). F1 skor, kesinlik ve hassasiyetin bir fonksiyonudur (Eşitlik 13). Genel doğruluk, doğru sınıflandırılan noktaların oranını ölçer.

Kesinlik $=\frac{G P}{G P+Y P}$

Hassasiyet $=\frac{G P}{G P+Y N}$

F1 skor $=2 \frac{\text { Kesinlik } . \text { Hassasiyet }}{\text { Kesinlik+ Hassasiyet }}$

GP, tahmin edilen ve gerçek etiketi pozitif olan noktaların sayısıdır. Yanlış pozitif (YP), pozitif olarak tahmin edilen ancak gerçek etiketleri negatif olan noktaların sayısını ifade eder. Yanlış negatif (YN), negatif olarak tahmin edilen ancak gerçek etiketleri pozitif olan noktaların sayısını ifade eder (Alpaydın, 2010).

\section{Uygulama}

$\mathrm{Bu}$ çalışma kapsamında, seçilen bölgenin nokta bulutu verisi Agisoft Photoscan yazılımı üzerinden üretilmiştir. Fotogrametrik değerlendirme sonucunda 23080227 nokta içeren bir yoğun nokta bulutu üretilmiştir. Üretilen nokta bulutu verisi Şekil 4'te gösterilmiştir. Nokta bulutu üretimi tamamlandıktan sonra nokta bulutu etiketleme işlemine geçilmişstir. Yapılan etiketleme sonucu nokta bulutu dört ayrı sınıfa bölünmüştür. Bu sınıflar bina, ağaç, yer seviyesi nesneleri ve araç olarak belirlenmiştir. Böylece sınıflandırma işleminin doğruluk analizini yapmak için yer doğruluğu verisi üretilmiştir. Etiketlenen nokta bulutu Şekil 4'te gösterilmiştir. 


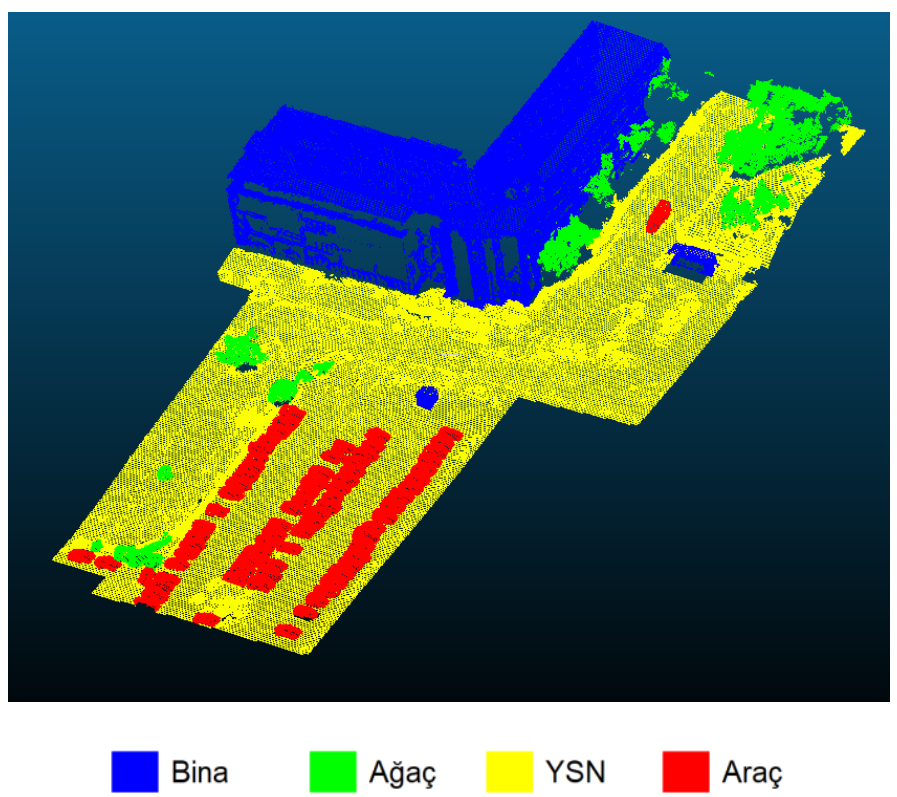

Şekil 4: Etiketlenmiş nokta bulutu.

Nokta bulutu üretiminden sonra geometrik özellikler hesaplanmıştır. Geometrik özelliklerin hesaplanmasındaki en önemli parametre komşuluk yarıçapıdır. Komşuluk yarıçapı merkez noktanın etrafında belirli bir yarıçapa sahip küre ile belirlenmiştir. Küre içerisinde bulunan noktalar merkez noktanın komşu noktaları olarak adlandırılır. Komşuluk alanı içindeki noktaların geometrik ilişkilerine bağlı olarak geometrik özellikler belirlenir. Şekil 5 'te hesaplanan geometrik özellikler görselleştirilmiş̧ir.

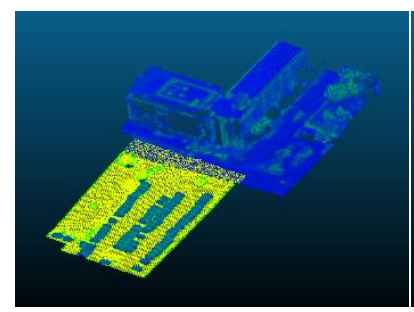

(a)

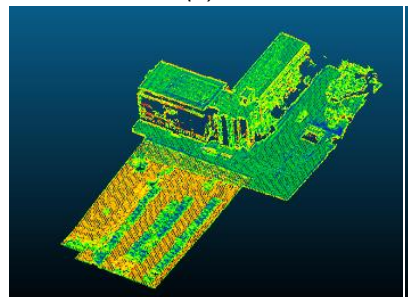

(e)

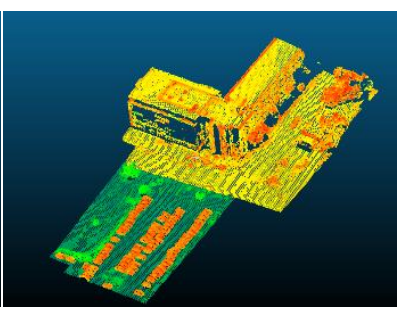

(b)

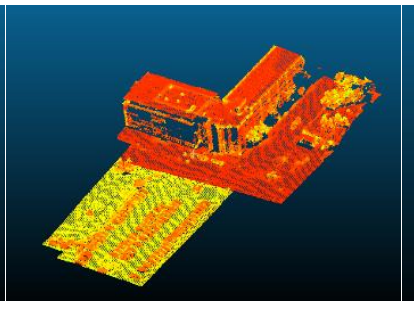

(c)

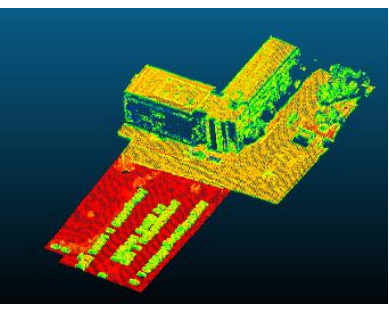

(d)

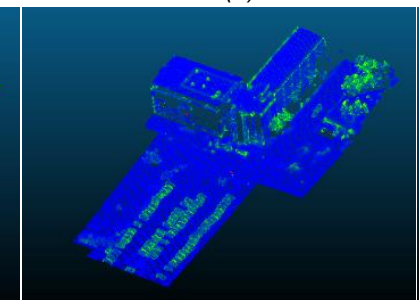

(f)

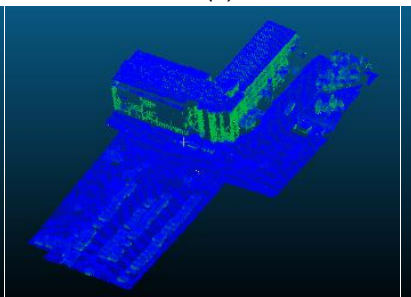

(g)

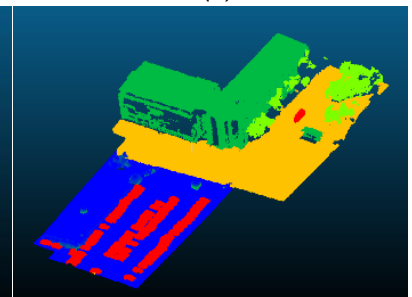

(h)

Şekil 5: Çalışmada kullanılan geometrik özelliklerin gösterimi. (a) özdeğerlerin toplamı; (b) omnivaryans; (c) özentropi; (d) anistropi; (e) düzlemsellik; (f) yüzey değişimi; (g) küresellik; (h) dikeylik

Elde edilen nokta bulutu üzerinden algoritmalarda kullanılmak üzere her bir sınıf için eğitim verileri seçilmiştir. Seçilen bu eğitim verileri her bir sınıf için 250000 noktadan oluşmaktadır. Böylece dengeli bir eğitim verisi oluşturulmuştur. Dengesiz eğitim verileri sınıflandırma sonucunda eğitim verisi fazla olan sınıfa eğilimin oluşmasına sebep olabilmektedir. Eğitim verilerinin seçilmesinin ardından Python programlama dili ile kodlama yapılmıştır. RO ve ÇKA yöntemleri için Sci-kit learn kütüphanesinden (URL-1) faydalanılmıştır. RO yönteminde uygun parametreler deneysel olarak en iyi sonuçlar elde edilecek şekilde seçilmiştir. Ağaç sayısı 100, ayırma kriteri olarak Gini indeksi ve maksimum derinlik de 2 olarak belirlenmiştir. ÇKA 
yönteminde gizli katman boyutu 100, aktivasyon fonksiyonu ReLU, optimizer olarak ‘Adam' ve maksimum iterasyon 200 olarak seçilmiştir. Eğitim verileri kullanılarak algoritmalar eğitildikten sonra bütün nokta bulutu sınıflandırılmıştır.

\section{Tartışma}

Çalışma sonuçları her bir sınıfa ait kesinlik, hassasiyet, F1 skoru ile genel doğruluk değerleri ile sunulmuştur. Ayrıca sonuçların dağılımının daha iyi yansıtılması için hata matrisleri de sunulmuştur. Elde edilen sonuçlara göre Rastgele Orman algoritması genel doğruluk olarak \%78.54, Çoklu Katman Algılayıcı algoritması ile \%89.88 oranında genel doğruluk elde edilmiştir.

Algoritmaların sınıf bazında doğrulukları da incelenmiştir. RO algoritmasının sonuçlarına göre, bina sınıfının yüksek kesinlik ile tespit edilmesine rağmen, bina sınıfının hassasiyeti düşüktür. Özellikle geometrik yapılarının düzleme benzemesinden dolayı YSN sınıfına ait noktaların bir kısmının bina olarak sınıflandırıldığı görülmektedir. YSN sınıfının hassasiyetinin \%99.57 olduğu görülmektedir. Bu YSN sınıfına atanan noktaların neredeyse tamamının doğru olduğu anlamına gelmektedir. Genel doğruluk ve F1 skor değerlerine göre en yüksek değerlere sahip sınıf ise araç sınıfıdır. Araç sınıfı \%87.53 F1 skora ve \%93.59 genel doğruluğa sahiptir. Ağaç sınıfının bina sınıfına benzer şekilde duyarlılığı, hassasiyetinden düşüktür. Bunun sebebi gerçekte bina sınıfına ait olan bazı noktaların ağaç sınıfı olarak tahmin edilmesidir. Bina yapılarının yan cepheleri nokta bulutunda eksik ve gürültülü olduğu için ağaç sınıfının düzensiz yapısı ile benzerlik göstermektedir. Bu durumda iki sınıfa ait noktalarda birbirine benzer geometrik özellikler hesaplanmaktadır.

ÇKA algoritmasının sonuçlarına göre, özellikle YSN sınıfında önemli bir artış görülmektedir. RO algoritmasında bina ile karışan noktalar, ÇKA ile doğru şekilde sınıflandırılmıştır. Veri seti içerisinde YSN sınıfı diğer sınıflardan daha fazla ağırlığa sahip olduğu için bu durum sınıflandırma doğruluğunu da önemli derecede arttırmıştır. Bina sınıfının genel doğruluğu RO’ya göre yaklaşık \%7 azalarak \%85.67 olmuştur. Bina sınıfı diğer sınıfların her biriyle karışmıştır. Ancak yine de bina çıkarımı için \%85 üzerinden doğruluk elde edilmiştir. Ağaç sınıfının kesinlik değeri \%58.21 iken, hassasiyet değeri \%89.44’tür. Yerde bulunan hafif çimenlik alanlar referans veride YSN olarak etiketlenmiştir. ÇKA algoritması bu bölgeleri ağaç sınıfına atamıştır. Bunun en önemli sebebi bu bölgelerin ağaç ile benzer renk değerlerine sahip olmasıdır. Araba sınıfının metriklerinde de RO’ya göre düşüş olmuştur. Kesinlik değeri \%79.55 olarak, hassasiyet değeri ise \%56.27 olarak tespit edilmiştir. Buna göre gerçekte araç olan noktalar genelde tespit edilmesine rağmen, diğer sınıflara ait noktalardan da araç sınıfına atananlar bulunmaktadır. Özellikle bina sınıfı ile araç sınıfı arasında bir karışıklık mevcuttur. Özellikle bina yan cephelerindeki noktalarda araç olarak sınıflandıran noktalar mevcuttur. Ayrıca araçların tavanları düz olduğu için ÇKA yöntemi o bölgeleri YSN olarak sınıflandırmıştır. Tüm bu değerler göz önüne alındığında ÇKA yönteminin RO’ya göre fotogrametrik nokta bulutu sınıflandırması için daha yüksek doğruluğa sahip olduğu görülmektedir. Özellikle YSN sınıfı açısından büyük bir iyileştirme söz konusudur. Sınıflara ait doğruluk metrikleri Tablo 2'de, hata matrisleri Tablo 3 ve Tablo 4'te sunulmuştur. Nokta bulutunun sınıflandırma sonucu Şekil 6 ve Şekil 7'de gösterilmiştir. 


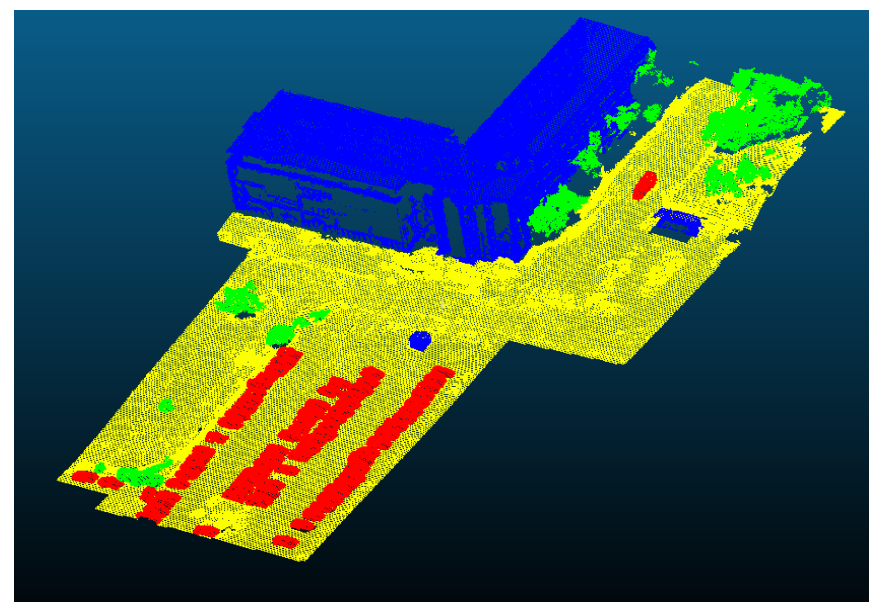

Bina

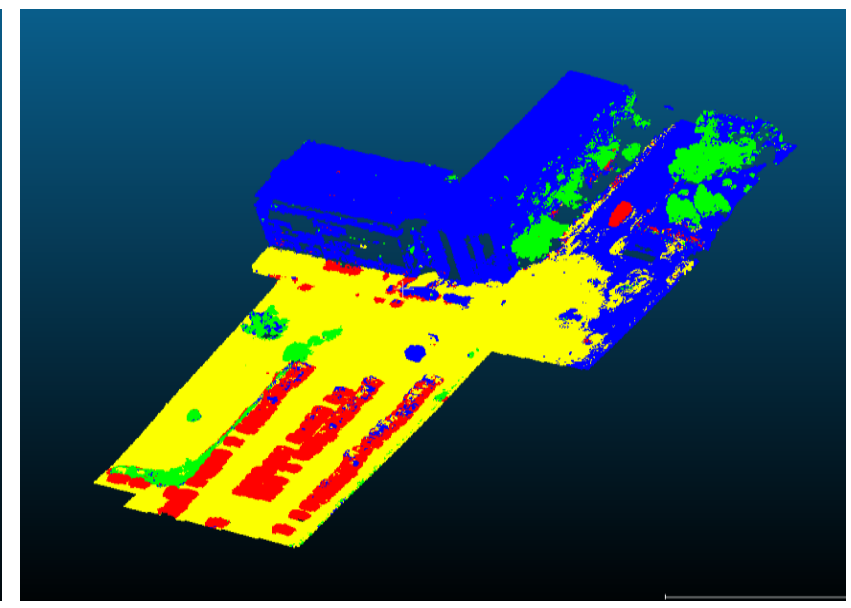

YSN

Araç

Şekil 6: Referans nokta bulutu (solda) ve RO algoritması sonucu (sağda).

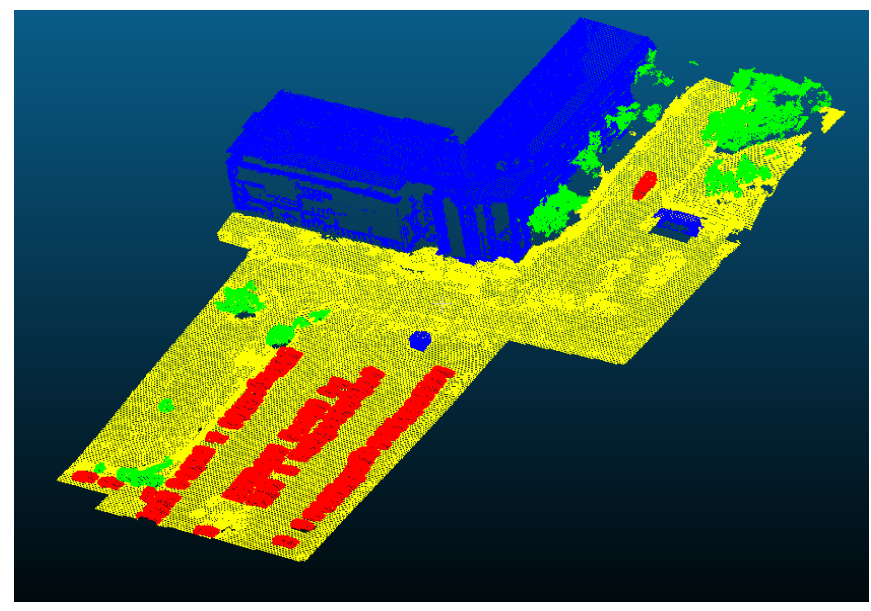

Bina

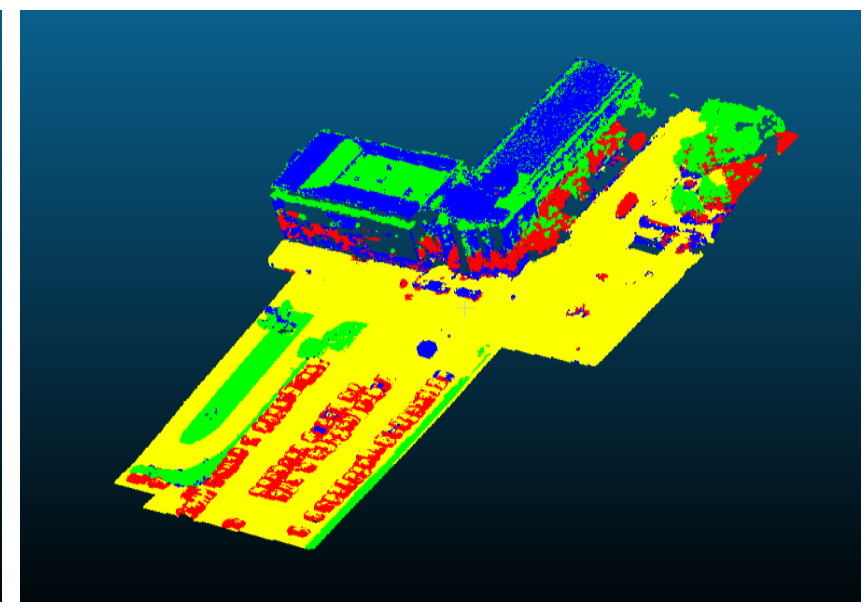

Araç

Şekil 7: Referans nokta bulutu (solda) ve ÇKA algoritması sonucu (sağda)

Tablo 2: Yöntemlerin karşılaştırmalı doğruluk metrikleri (Değerler \% olarak verilmiştir).

\begin{tabular}{|c|c|c|c|c|c|c|c|c|}
\hline \multirow{2}{*}{ Sinıf } & \multicolumn{2}{|c|}{ Kesinlik } & \multicolumn{2}{|c|}{ Hassasiyet } & \multicolumn{2}{|c|}{ F1 Skoru } & \multicolumn{2}{|c|}{ Genel Doğruluk } \\
\hline & $R O$ & $C ̧ K A$ & $R O$ & $C \zeta K A$ & $R O$ & $C \zeta K A$ & $R O$ & $C \zeta K A$ \\
\hline Bina & 93.62 & 85.67 & 56.78 & 85.06 & 70.69 & 85.36 & 93.62 & 85.67 \\
\hline Ăgaç & 87.86 & 58.21 & 65.83 & 89.44 & 75.27 & 70.52 & 87.86 & 58.21 \\
\hline$Y S N$ & 69.92 & 95.82 & 99.57 & 98.07 & 82.15 & 96.93 & 69.92 & 95.83 \\
\hline Araç & 93.56 & 79.55 & 82.23 & 56.27 & 87.53 & 65.92 & 93.56 & 74.83 \\
\hline & & & Ăğ|$_{1}$ & Ortalama & 79.00 & 90.00 & 78.54 & 89.88 \\
\hline
\end{tabular}

Tablo 3: RO sonucu hata matrisi.

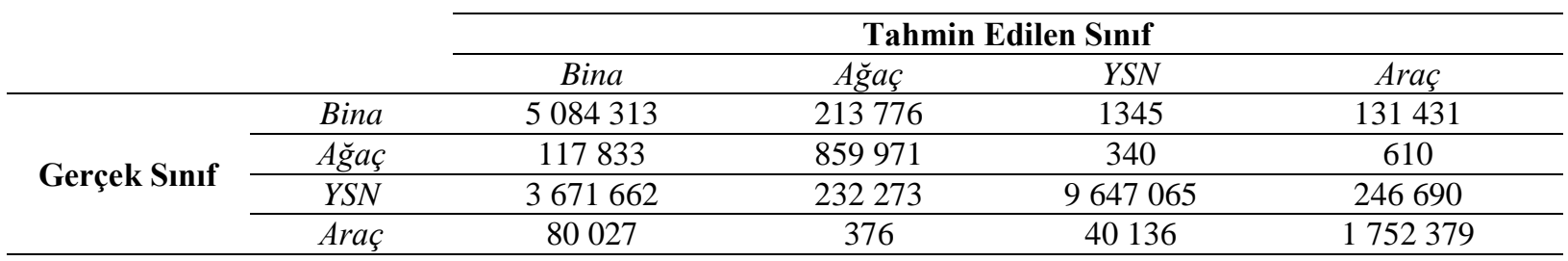


Tablo 4: ÇKA sonucu hata matrisi.

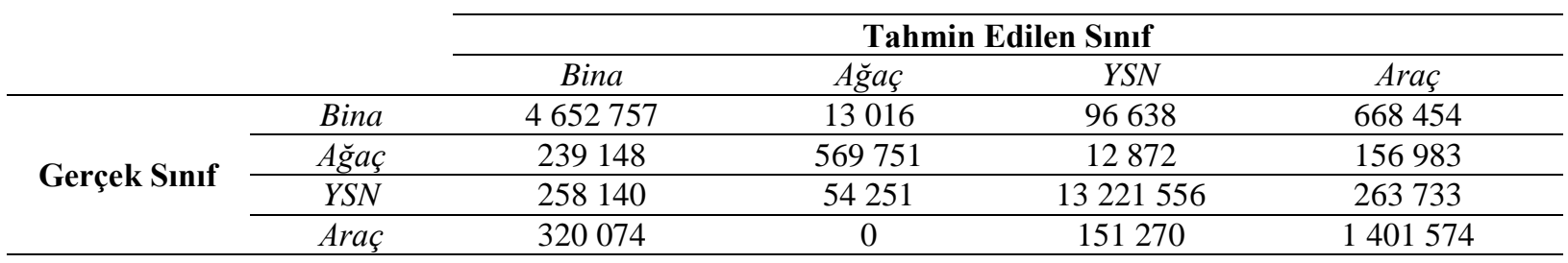

Geometrik özellikler değerlendirildiğinde RO algoritması için YSN sınıfını bina sınıfında ayırt etmek için seçilen özellikler yeterli olmamaktadır. Ancak ÇKA algoritması bu özellikler ile YSN ve bina sınıflarını ayırt edebilmektedir. Böylece yapay sinir ağı temelli ÇKA algoritmasının benzer geometrik yapıya sahip nesneleri ayırt etmede kullanılabileceği sonucu çıkarılmaktadır. Ancak bina, ağaç ve araba gibi sınıflarda RO algoritması ön plana çıkmaktadır. Bu sınıflar için RO’nun ağaç yapısının daha uygun olduğu söylenebilir. YSN sınıfının veri seti içerisinde oran olarak fazla olması bu konudaki başarısı sayesinde ÇKA yönteminin ön plana çıkmasını sağlamıştır. Nokta bulutu verileri genellikle büyük ve karmaşık veriler oldukları için makine öğrenmesi yaklaşımları yerine yapay sinir ağı yaklaşımlarını tercih etmek daha doğru olacaktır. Uygun parametre ve özellik seçimi ile ÇKA yönteminin doğruluklarının her sınıfta arttırılması mümkün olabilir.

\section{Sonuç ve Öneriler}

$\mathrm{Bu}$ çalışmada fotogrametrik yöntemler ile elde edilen nokta bulutunun makine öğrenmesi teknikleri ile sınıflandırılması incelenmiştir. Noktaların özellik uzaylarını oluşturmak için bir noktanın komşu noktaları yardımıyla hesaplanan geometrik özellikler kullanılmıştır. Sınıflandırma işlemi için RO ve ÇKA yöntemleri kullanılmıştır. Literatürdeki çalışmalar göz önüne alındığında fotogrametrik nokta bulutu ile ilgili yapılan çalışmalar kısıtlıdır. Yeni bir veri seti üretmek emek-yoğun bir iştir. $\mathrm{Bu}$ çalışmada kullanılan veri seti elle etiketlenmiştir. Gelecek çalışmalar için daha fazla özellik eklenerek çalışma genişletilebilir. Ayrıca literatürde farklı sensörler ile elde edilen hazır veri setleri bulunmaktadır. Farklı yöntemler ve farklı veri setleri ile daha geniş kapsamlı incelemeler yapılabilir. Gelişen teknoloji nokta bulutlarının kullanım alanları artmaktadır. Sadece veriyi elde etmek değil veriden bilgi çıkarımı da değerli hale gelmektedir. Makine öğrenmesi yaklaşımları fotogrametrik nokta bulutlarından anlamlı bilgi çıkarımı için büyük bir potansiyele sahiptir.

\section{Çıkar Çatışması Beyanı}

Yazarlar, bu çalışmada bilinen ilgili herhangi bir finansal veya finansal olmayan çıkar çatışması olmadığını beyan eder.

\section{Yazar Katkısı}

Muhammed Enes Atik: Fikir, Tasarım, Yazım, Makale değerlendirme. Ömercan Güngör: Yazım, Literatür taraması, Analiz ve yorumlama, Veri toplama ve işleme. Engin Keskin: Yazım, Literatür taraması, Analiz ve yorumlama, Veri toplama ve işleme. Zaide Duran: Tasarım, Denetleme, Finansman, Makale değerlendirme. 


\section{Kaynaklar}

Abdullah, M. H. A., Othman, M., Kasim, S., Saharuddin, S. S., \& Mohamed, S. A. (2020). A spiking neural networks model with fuzzyweighted K-nearest neighbour classifier for real-world flood risk assessment. In International Conference on Soft Computing and Data Mining, 222-230.

Akar, Ö., \& Güngör, O. (2012). Rastgele orman algoritması kullanılarak çok bantlı görüntülerin sınıflandırılması. Jeodezi ve Jeoinformasyon Dergisi, 1(2), 139-146.

Alpaydin, E. (2010). Introduction to machine learning ( $2^{\text {nd }}$ Edition). MIT press.

Arı, A., \& Berberler, M. E. (2017). Yapay sinir ağları ile tahmin ve sınıflandırma problemlerinin çözümü için arayüz tasarımı. Acta Infologica, 1(2), 55-73.

Atik, M. E., \& Duran, Z. (2021). Classification of Aerial Photogrammetric Point Cloud Using Recurrent Neural Networks. Fresenius Environmental Bulletin, 30(4 A), 4270-4275.

Atik, M. E., Duran, Z., \& Seker, D. Z. (2021). Machine Learning-Based Supervised Classification of Point Clouds Using Multiscale Geometric Features. ISPRS International Journal of Geo-Information, 10(3), 187.

Becker, C., Rosinskaya, E., Häni, N., d'Angelo, E., \& Strecha, C. (2018). Classification of aerial photogrammetric 3D point clouds. Photogrammetric Engineering \& Remote Sensing, 84(5), 287-295.

Belgiu, M., Tomljenovic, I., Lampoltshammer, T. J., Blaschke, T., \& Höfle, B. (2014). Ontology-based classification of building types detected from airborne laser scanning data. Remote Sensing, 6(2), 1347-1366.

Breiman, L. (2001). Random forests. Machine learning, 45(1), 5-32.

Cabo, C., Ordóñez, C., Sáchez-Lasheras, F., Roca-Pardiñas, J., \& de Cos-Juez, J. (2019). Multiscale supervised classification of point clouds with urban and forest applications. Sensors, 19(20), 4523.

Donmez, S. O., Ipbuker, C. (2018) Investigation on Agent Based Models for Image Classification of Land Use and Land Cover Maps, Proceedings. 39th Asian Conference on Remote Sensing: Remote Sensing Enabling Prosperity, ACRS 2018, 4, pp. 2005-2008

Guo, B., Huang, X., Zhang, F., \& Sohn, G. (2015). Classification of airborne laser scanning data using JointBoost. ISPRS Journal of Photogrammetry and Remote Sensing, 100, 71-83.

Hastie, T., Tibshirani, R., \& Friedman, J. (2010). The elements of statistical learning: data mining, inference, and prediction (Second Edition). Springer Science \& Business Media.

Li, X., Cheng, X., Chen, W., Chen, G., \& Liu, S. (2015). Identification of forested landslides using Lidar data, object-based image analysis, and machine learning algorithms. Remote sensing, 7(8), 9705-9726.

Lin, C. H., Chen, J. Y., Su, P. L., \& Chen, C. H. (2014). Eigen-feature analysis of weighted covariance matrices for Lidar point cloud classification. ISPRS Journal of Photogrammetry and Remote Sensing, 94, 70-79.

Plaza-Leiva, V., Gomez-Ruiz, J. A., Mandow, A., \& García-Cerezo, A. (2017). Voxel-based neighborhood for spatial shape pattern classification of Lidar point clouds with supervised learning. Sensors, 17(3), 594.

Qin, W., Guo, W., Liu, X., \& Zhao, H. (2019). A Novel Scheme for Recruitment Text Categorization Based on KNN Algorithm. In International Conference on Smart Computing and Communication, 376-386.

Vosselman, G., Coenen, M., \& Rottensteiner, F. (2017). Contextual segment-based classification of airborne laser scanner data. ISPRS journal of photogrammetry and remote sensing, 128, 354-371.

Weinmann, M., Jutzi, B., Hinz, S., \& Mallet, C. (2015). Semantic point cloud interpretation based on optimal neighborhoods, relevant features and efficient classifiers. ISPRS Journal of Photogrammetry and Remote Sensing, 105, 286-304.

URL-1: https://scikit-learn.org/stable/modules/neural_networks_supervised.html 